\title{
SOBRE LOS LÍMITES DEL LENGUAJE Y LAS LIMITACIONES DE LA FENOMENOLOGÍA
}

\author{
Hacia uná crítica fenomenológica del lenguaje
}

\author{
Antonio Zirión Quijano \\ Seminario-Taller de Estudios y Proyectos de Fenomenología Husserliana \\ UNAM / UMSNH
}

En un manuscrito inédito, ${ }^{1}$ que no forma parte de una obra destinada a publicación y que puede situarse, cuando más tarde, en los primeros años que pasó en México, José Gaos enuncia cuatro tesis que, a mi juicio, tendrían que interesar a todos los estudiosos de la fenomenología, pero sobre todo a los que nos hemos dedicado, de un modo u otro, al lenguaje de la fenomenología y a su ínevitable entrecruzamiento con una fenomenología del lenguaje. ${ }^{2}$ La primera de ellas se titula "El postulado de la Fenomenología", y dice así: "Toda la Fenomenología reposa sobre este postulado: la explicitabilidad de todo el saber implícito en la inteligencia y uso de los términos del lenguaje". La segunda, que se titula "El arcaísmo de este postulado", reza: "Este postulado es una última derivación de la idea griega de la definibilidad universal". La tercera, titulada "La teoría del decir y de lo decible", dice esto: "Toda filosofía requiere una teoría de lo decible y de los modos de decirlo". Y finalmente, la cuarta, que se titula, "La imprecisión de lo imprecisable", afirma: "Esta teoría debe admitir que no todo es definible, ni siquiera decible. Que no todo es precisable. Que muchas cosas no pueden sino narrarse, sugerirse narrativamente". En el folio siguiente al que contiene estas cuatro tesis, se

\footnotetext{
${ }^{1}$ Manuscrito inédito en el folio 36277, carpeta 37 (Fondo 2) del Archivo de José Gaos en el Instituto de Investigaciones, UNAM, México.

2 Por "fenomenología" entiendo aquí la fenomenología husserliana, sin mayor discusión ni justificación.
} 
lee una escueta frase que, más que una tesis, parece una mera perplejidad. La frase reza: "De la razón de hablar de lo que se vive sin habla".

Estas tesis no interesan tanto por lo que concierne a la caracterización que se hace en ellas de la fenomenología. Aunque en ella se llega al extremo de darle al fenomenólogo ese curioso papel de lexicỏgrafo universal y exhaustivo, de filólogo y etimólogo dedicado a extraer del lenguaje todo el saber que encierra, la comprensión -o la mala comprensión- de la fenomenología como un análisis de conceptos no fue nada rara durante las primeras décadas de la difusión de la fenomenología. Pero no voy a indagar ahora las razones o sinrazones de estas nociones. Sólo hay que decir, desde luego, que independientemente de la factibilidad de esa tarea de explicitación total del saber contenido en el lenguaje, la fenomenología puede eximirse con toda justificación de ponerla en prâctica, pues para ella, dicho simplemente, el lenguaje no es la fuente del saber. Para mi propósito, es mucho más interesante el cotejo que puede hacerse de las dos últimas tesis de Gaos con las verdaderas intenciones, si puede decirse así, de la fenomenología. Pues aunque no de modo explícito, parece que Gaos está también refiriéndose a la fenomenología al decir que "Toda filosofia requiere una teoría de lo decible y de los modos de decirlo" y que "Esta teoría debe admitir que no todo es definible, ni siquiera decible", no solamente como si en la fenomenología faltara de hecho esa teoría-que de hecho sí falta-, sino como si en ella se sostuviera la decibilidad o expresabilidad universal, la decibilidad de todo.

Ante estas tesis, enunciadas o no en referencia a la fenomenología, me parece posible sostener que ésta puede admitir que no solamente no todo es definible, sino que, precisamente, como lo dice Gaos, no todo es siquiera decible, y que aunque eso mismo que es indecible pudiera ser narrativamente sugerido, esa narración, justo por ser lingüística, no llega o no llegaría a saltar el abismo de la indecibilidad esencial de eso "que se vive sin habla". Vamos a tratar de circunscribir; desde la fenomenología, esta indecibilidad esencial, con lo cual acaso logremos hacer ver, a la vez que un límite muy bien precisable del lenguaje, la capacidad de la fenomenología para abordar esta temática con sus propios términos, lo que significará eliminar las barreras que las tesis de Gaos parecían querer imponerle. Es más, creo que sólo desde la fenomenología puede reflexionarse con fruto acerca de esa perplejidad que Gaos dejó en el aire: sólo una fenomenología del lenguaje que sea a la vez, por ese señalamiento de sus límites, una crítica del lenguaje, puede ahondar en "la razón de hablar de lo que se vive sin habla" y acaso también reivindicarla.

Es bien sabido que Husserl no desarrolló una fenomenología del lenguaje en toda forma. Se ha dicho incluso que en la fenomenología se repite el 
"abismal olvido del lenguaje que ya caracterizó al idealismo trascendental". Pero también es cierto que en varias de sus obras publicadas hay partes importantes dedicadas al tema de la expresión y la significación, o al tema del logos, una de cuyas principales acepciones es el de palabra o locución, es decir, lenguaje, de modo que hay en ellas bases más que suficientes para iniciar la construcción de una teoría fenomenológica del lenguaje completa. Lo que a Husserl le ha faltado, lo que se echa de menos, es una consideración del papel del lenguaje, no sólo en la génesis y la evolución de la cultura científica, acerca de lo cual esbozó también algunas reflexiones, ${ }^{4}$ sino en las de la cultura y la historia humanas en general, en todos los aspectos, pues, de la vida humana, desde los más básicos o primitivos hasta los más elevados. Es cierto que en este punto la fenomenología husserliana contrasta con las principales tendencias tanto de la filosofía analítica como del resto de la filosofía continental, e incluso con filósofos contemporáneos o ligeramente posteriores a Husserl que también se hacen llamar fenomenólogos. Pero hablando de contrastes, también en relación con este tema hay que recordar el sentido y el propósito de la tarea de la fenomenología husserliana: no se le puede exigir a una filosofía que se propone a sí misma un trabajo de equipo, comunitario, que ha de abarcar a varias generaciones sólo en la edificación de los cimientos, la resolución de los principales problemas de la filosofía o siquiera doctrinas bien elaboradas acerca de ellos. Ello equivale a tratar a la fenomenología como lo que nunca se propuso ser. Lo cierto es que la cuestión del lenguaje, sea cual sea su importancia histórica, antropológica o filosófica, entra sin duda, como cuạlquier otra de su calado, en el programa de la fenomenología, y esto debiera de ser bastante para no lamentar su ausencia y ponernos a trabajar en ella. Para bien o para mal, no todo nos lo van a dar ya digerido nuestros grandes maestros. Respecto del punto que nos concierne, Husserl dice literalmente en Lógica formal y lógica trascendental: "El hombre no 'expresa' verdaderamente en el lenguaje toda su vida anímica, ni puede expresarla", 5 pero no nos explicó de modo explícito y claro por qué.

Pero, por otro lado, las principales críticas que en relación con el tema del lenguaje se han dirigido a la fenomenología husserliana, aparte esa crítica general de que en ella se da un "olvido del lenguaje", se dirigen precisamente contra la teoría de la significación y la expresión expuesta en lạs distintas

3 Hans-Georg Gadamer, "Destruktion und Dekonstruktion", en Wahrheit und Methode. 2: Ergänzungen, Gesammelte Werke, vol. 2, Tübingen: Mohr, 1986, p. 361. Versión casteIlana, aquí ligeramenter modificada, de Manuel Olasagasti, Verdad y método II, Salamanca: Ediciones Sígueme, 2. ${ }^{\mathrm{a}}$ ed., 1994, p. 349.

${ }^{4} \mathrm{Cf}$."El origen de la geometría".

5 §, p. 71 de la versión castellana de Luis Villoro, México: UNAM, 2. ${ }^{2}$ ed., 2009. 
obras publicadas. Me refiero, sobre todo, a las críticas de Jacques Derrida, que se dirigen a puntos muy específicos de las descripciones husserlianas, pero que a la vez implican su caracterización como un buen modelo de eso que él llama una "metafísica de la presencia". Lo señalo sólo para enmarcar mi exposición, pues no voy a entrar en ninguna de estas críticas, y eso que, por momentos, se puede sentir la tentación de hacerlo. El mismo Derrida, cuando comenta y critica las secciones del Libro primero de las Ideas de Husserl en que éste se refiere al "logos", al significar y a la significación, a las vivencias expresivas y su relación con las expresadas, etc., desdeña expresamente, pero sin mayor comentario, es decir, como algo verdaderamente despreciable, la posibilidad de "producir una crítica del lenguaje a partir de las riquezas inefables del sentido". 6

Ahora bien, sin duda esta crítica del lenguaje puede adquirir visos demasiado románticos para nuestro buen gusto posmoderno y deconstruccionista, sobre todo si con ella se nos puede desequilibrar la balanza entre esas riquezas inefables del sentido y las innegables riquezas del lenguaje (principalmente del escrito): Pero con la fenomenología no se trata de desequilibrar nada, sino precisamente de poner las cosas en su lugar de la manera más sobria posible. Aunque el lector interesado le habría agradecido alguna explicación de su desdén, habla bien de la perspicacia de Derrida que haya visto al menos la posibilidad de esa crítica del lenguaje a partir de las inefabilidades del sentido precisamente en esos parágrafos de Ideas I en los que, entre otras cosas, Husserl escribió que "toda mención en sentido noemático (y en verdad en cuanto núcleo noemático) de un acto cualquiera es expresable mediante 'significaciones"'? Sin embargo, un examen detenido de los mismos parágrafos hace ver con claridad esa posibilidad. Creo que podemos empezar por esto. Dejaré a un lado, por ahora, otras exposiciones o planteamientos que acerca de esta temática se encuentran en otras obras de Husserl. ${ }^{8}$

${ }^{6}$ En su escrito "La forma y el querer-decir. Notas sobre la fenomenología del lenguaje", publicado en la Revue internationale de philosophie, 81, 1967, pp. 277-299. En traducción española en Márgenes de la filosofia, trad. de Carmen González Marín, Madrid: Ediciones Cátedra, Colección Teorema, 3. ${ }^{\mathrm{a}}$ ed., 1998, pp. 193-212. La cita en p. 211.

${ }^{7}$ Ideen zu einer reinen Phänomenologie und phänomenologische Philosophie. Erstes Buch: Allgemeine Einführung in die reine Phänomenologie. 1. Halbband. Text der 1.-3. Auflage. Neu herausgegeben von Karl Schuhmann. Den Haag: Martinus Nijhoff, 1976. Vol. III/1 de Husserliana. Edmund Husserl Gesammelte Werke, p. 286. Utilizo mi traducción, en prensa.

${ }^{8}$ Dejo a un lado la exposición mucho más conocida, y también más temprana, de la primera de las Investigaciones lógicas (titulada "Expresión y significación"), y la más especializada de la Sexta, pero también los tomos complementarios de la edición de Husserliana de las Investigaciones lógicas, en los que se publican los borradores de la reelaboración de la Sexta Investigación, y, principalmente, los textos "Acerca de la fenomenología de la expresión y del 
En Ideas I, Husserl introduce formalmente el tema de la expresión y la significación en el § 124. El de la expresión es, como se sabe, un nuevo estrato por encima del estrato básico de los actos, el cual, como tal, posee, antes o independientemente de su posible expresión, un sentido, e incluso un sentido más o menos explicitado. La nueva capa de la expresión es de hecho una capa bilateral, dada la necesidad de distinguir su lado corpóreo o sensual (el sonido verbal) de su lado no-sensual o no-corpóreo (el lado de la significación propiamente dicha). Como Husserl, no consideraré aquí la relación entre estos dos lados, la forma de su unión, etc., lo cual constituye un tema importante por sí mismo pero que aquí puede omitirse. Con él, se omite la cuestión de si puede vivirse una mera significación sin su lado corpóreo, es decir, sin la palabra, de la índole que sea. En todo caso, para las consideraciones que haremos, resulta indiferente si una palabra (un sonido verbal o un signo escrito o gestual) está presente o dada o no lo está.

Lo propio del expresar, esto es, del significar, consiste en dar "cuño conceptual", o la peculiar forma de la "conceptualidad" al sentido noemático de un acto y de su referencia a una objetividad. Percibo un mirlo que echa a volar y digo, o sólo pienso, con sentido, "Un mirlo echa a volar", como en el conocido ejemplo de la 6a. Investigación Lógica. Como aquí, en la exposición del ejemplo, tuve que imprimir conceptualmente el nóema perceptivo (estrictamente, fantasivo) para expresarlo cuando me referí a él en su condición pre-expresa (al decir, precisamente, "Percibo un mirlo que écha a volar..."), toda posible discrepancia entre el nóema perceptivo, hasta ahora no expresado, o la percepción como tal, y su expresión, permanece oculta. Es más, como Husserl nos recuerda, esta expresión de la percepción puede incluso tomar el nombre de percepción expresa, debido al hecho de que hay una coincidencia en esencia entre la capa expresiva (la que expresa) y la capa que recibe expresión (la expresada). A pesar de ello, Husserl observa con cierto énfasis cuán poca justicia se le ha hecho en la literatura (en la de su tiempo, claro) a los grandes problemas relativos a la relación entre las "vivencias expresas" y las "no expresas", y a lo que "experimentan estas últimas al sobrevenir el expresarlas". ${ }^{9}$ Entre esos problemas, Husserl menciona sobre todo la distinción entre, por un lado, el sentido y los momentos esenciales que residen en lo pre-expreso, y, por el otro, la significación del fenómeno expresivo mismo y los momentos que le son propios. Todos podemos advertir fácilmente la distancia, por así decirlo, que hay entre el sentido de la percepción

conocimiento" redactados para la nueva versión de esta misma Investigación. También dejo a un lado el tratamiento del logos en Lógica formal y lógica trascendental.

9 Hua III/1, 287. 
singular del mirlo que echa a volar, y la significación confinada en su expresión, o la significación de esta expresión como tal. Puede decirse que todos los problemas o cuestiones que se discuten o que son programáticamente introducidos en los parágrafos restantes acerca de la expresión o el logos, tocan de un modo $u$ otro este vasto e importante tema de la relación entre el estrato del sentido pre-expreso y el estrato de la expresión o, más precisamente, de la significación de la expresión. En este espacio, o en este hiato, se sitúan también estas reflexiones.

El $\S 126^{10}$ está dedicado en su integridad a los temas de la generalidad y la integridad de la expresión. Husserl menciona en primer lugar la falta de integridad que consiste en el hecho de que la expresión da cuño significativoconceptual sólo a una parte de las formas y materias sintéticas del sustrato (del sentido que ha de ser expresado 'o que busca ser expresado). En el ejemplo husserliano del gritar hacia la casa "¡El coche! ¡Los huéspedes!”,", el sustrato entero de sentidos vividos que están buscando expresión es mucho más complejo que el mero sentido perceptivo de la percepción del coche más el sentido no-intuitivo de la representación de los huéspedes (que están en el interior del coche y no son aún visibles). Dejamos de lado esta falta de integridad, que Husserl trata aparentemente como accidental, porque no podemos encontrar en ella ninguna amenaza a las capacidades del lenguaje, esto es, ningún ejemplo de sus límites. Siempre podemos fingir la expresión completa que corresponde a la incompleta; por ejemplo: "El coche en el que vienen los huéspedes que hemos estado esperando está por fin aproximándose a la casa", o algo similar. De modo que nos ocupamos en lo que sigue sólo de expresiones completas (reales o simuladas), esto es, en palabras de Husserl, con expresiones donde la capa superior expresiva está expresivamente extendida sobre toda la subcapa o todo el sustrato. ${ }^{12}$

La principal falta de integridad de la expresión, porque es esencial, es la que trae consigo su generalidad o su universalidad, siendo que toda vivencia, incluso las que se refieren a una generalidad, son singulares, individuales, únicas, aunque puedan ser clasificadas en un tipo o clase más o menos general. Husserl menciona las formas generales de las expresiones que corresponden

${ }^{10}$ Dejo a un lado el $\S 125$, acerca de las modalidades de la efectuación en la esfera de la expresión y el método de la clarificación, aunque estos temas podrían resultar a la larga muy interesantes, o incluso decisivos, en nuestra investigación.

11 Hua III/1, 291.

12 Como se verá por lo que sigue, esta falta de integridad accidental consiste en que no reciben expresión algunas partes del sentido objetivo, del núcleo noemático de la vivencia que se quiere expresar. Las expresiones completas en este sentido de integridad, sean reales o simuladas, son expresiones en que está expresado todo el núcleo noemático. 
a algunos de estos tipos de vivencias: el "ojalá" como expresión del deseo, el modo imperativo, que expresa la orden, el "pudiera ser", que expresa la conjetura, etc. Es mucho más interesante para nosotros, así sea un obvio corolario de esta esencial falta de integridad debida a la generalidad, la siguiente proposición: "Todo lo que en la unidad de la expresión determina con más detalle es a su vez expresado con generalidad". ${ }^{13}$ Esto quiere decir que si quisiera completar la expresión de mi percepción (digamos, "Un mirlo echa a volar") con la expresión de algunas particularidades o detalles de la percepción que no habían sido considerados en la primera expresión, la expresión resultante sería a su vez general: "Un hermoso mirlo de cuello blanco echa a volar con ímpetu repentino". O más: "Allí en el prado soleado y cubierto de un césped tan crecido que se deja mover por el viento, a una distancia que puedo calcular en cincuenta metros basándome en la longitud que sé que tiene la vereda que pasa junto al tronco en que acaba de posarse, y contra el cielo de un color azul cobalto tan intenso que casi parece el agua de un mar suspendido, echa a volar con ímpetu repentino, como si algo lo hubiera espantado, un hermoso mirlo de cuello blanco y larga cola...". Ni la vereda, el tronco, el azul del cielo, la belleza del mirlo, el cuello y su blancura, ni el ímpetu y su modo repentino de ocurrir, son aplicables en exclusiva a este único mirlo individual. Ni siquiera la expresión "Este mirlo" tiene un campo de aplicación o uso individual. Esto, que por supuesto no es ninguna novedad teórica, se expresa fenomenológicamente de esta manera: "En el sentido de la generalidad inherente a la esencia del expresar radica el que jamás puedan reflejarse en la expresión todas las particularidades de lo expresado. La capa del significar no es, y no es por principio, una especie de reduplicación de la subcapa". ${ }^{14}$

Aquí se nos ofrece ya un verdadero límite de la expresión, es decir, del lenguaje. Y me quiere parecer que no es solamente su límite más importante o de mayor peso, sino el único que tiene, si es cierta mi conjetura de que todos los demás límites que se le han querido atribuir no son en realidad límites del lenguaje, sino de otros rasgos, facultades o capacidades humanas, como por ejemplo del conocimiento interhumano, o del conocimiento sin más... Esto quiere también decirque la índole de indecibilidad queencontramosmásallá (o más acá) de este límite del lenguaje, es también, si la conjetura es cierta, la única auténtica indecibilidad. Además, quiere decir que está ya inserta en la naturaleza misma, en la esencia del lenguaje. No es un accidente ni un defecto de ciertas lenguas que otras podrían llegar a superar, o una propiedad de una etapa del desarrollo del lenguaje que pudiera llegar a ser superada en una etapa 
posterior. Nada de eso. Pero para entender bien lo que este límite significa, y en qué consiste la indecibilidad que entraña, no basta con decir que toda expresión lingüística es general, mientras que toda vivencia que aspira a ser expresada es individual. Esto es así, pero encierra algunos misterios.

Me apresuro a declarar, naturalmente, que el señalamiento de este límite no es ningún descubrimiento, ni en el pensamiento de Husserl ni mucho menos en esta conferencia. Tampoco en la historia de la filosofía es nada nuevo. Lo que puedo sostener (con la salvedad a que me obliga mi incultura) es que hasta ahora no se le ha dado suficiente atención dentro de la fenomenología, y por ello no ha sido expuesto con radicalidad ni en todas sus consecuencias...

Este límite era ya bien conocido, aunque no precisamente bien tolerado, entre los sucesores de Sócrates. Estilpón, de la escuela megárica, ${ }^{15}$ aseguraba que sólo existe lo singular, y que lo que se decía, por ejemplo, del hombre, no se decía de ninguno en particular y por ello no se decía ni de éste ni de aquél, e igualmente, como de la hierba se habla sólo en especie, afirmaba que esta hierba que un interlocutor le mostraba no era hierba. ${ }^{16}$ Quizá Estilpón aprendió esta doctrina de la impredicabilidad de los conceptos y la realidad exclusiva de lo particular y concreto del cínico Antístenes, ${ }^{17}$ quien llegó a afirmar que "de las cosas solamente puede decirse su nombre propio, que es único para cada una". ${ }^{18}$ En el extremo de esta línea de pensamiento se encuentra el Cratilo que Aristóteles nos presenta en su Metafísica como discípulo de Heráclito, que llegó a convencerse de que no podía decirse absolutamente nada y se contentaba con señalar con el dedo, pues mientras se habla todo cambia, y criticó al mismo Heráclito por creer que podemos bañarnos dos veces en un mismo río, cuando no podemos hacerlo ni una sola vez. ${ }^{19}$.

No voy a hacer el recorrido completo por la historia de la filosofía y de la literatura, aunque sería muy interesante hacerlo; pero por razones que pronto saldrán a relucir, no quiero dejar de mencionar un antecedente mucho más cercano a nosotros. Se trata de la propuesta que hizo en sus últimos años

15 h. 380/370-300/290.

${ }^{16}$ Cf. Guillermo Fraile, Historia de la filosofia. I. Grecia y Roma, Madrid: BAC, 1976, p. 268, y Diógenes Laercio, Vidas, opiniones y sentencias de los filósofos más ilustres, trad. José Ortiz y Sanz, El Ateneo, Bs. As., 1947, p. 170.

17 h. $444-365 / 370$.

18 Fraile, op. cit., p. 270.

${ }^{19}$ Cf. Aristóteles, Metafisica, 1010a 7 y ss., e Ingemar Düring, Aristóteles. Exposición e interpretación de su pensamiento, trad y ed. de Bernabé Navarro, México: UNAM, 1990, p: 938. No está claro qué pensaba este Cratilo que se lograba al señalar con el dedo... En algunas traducciones dice "alzar el dedo", en otra "mover el dedo"... 
José Vasconcelos ${ }^{20}$ de una "epojé inversa" y un "pensamiento paradisiaco". Con ella pretendía criticar a la fenomenología husserliana, que para él era un "entretenimiento de ideólogos", ${ }^{21}$ "invirtiendo" su "hipótesis fundamental", la "reducción' fenomenológica", porque ésta reemplaza "el mundo vivo de la naturaleza con una mediocre imaginería conceptual carente de vida". ${ }^{22}$ Entonces había que "ensayar el pensamiento sin ideas, hecho sólo de imágenes", y llegar "a la realidad en intuición directa, prescindiendo de los universales de uso corriente". Hay que contemplar el árbol concreto, ahí al centro de un prado, sin referencia a géneros o especies como pino o palmera; sólo atender al árbol particular rodeado de su césped también particular. Nada de pensar, pues al pensar se entra al mundo de las ideas y se pierde "el milagro vivo del ser, un ser que muere cuando se hace abstracción, revive sólo cuando" esplende, singular y concreto". Este "vivir dentro de lo concreto" se dice paradisiaco, "imaginando que así veían el mundo Adán y Eva, antes del pecado". Éste - el pecado- limitó las facultades de la conciencia "y nos obligó a construir esos aparatos de reducción, anteojos para la miopía, que son las voces abstractas que me veo obligado a usar cuando digo árbol, nombre que abarca una multiplicidad de vegetales diversos y lo que quisiera expresar y recordar es este árbol preciso de este día y de esta hora". ${ }^{23}$ Otra cosa sería si tuviera "un lenguaje que tuviese un nombre para cada cosa (que es lo debido, puesto que no hay dos iguales en la creación); y un infinito de nombres correspondiente al infinito de los seres". ${ }^{24}$ Como no lo poseo, tengo que abreviar, simplificar, y acudo a signos que "sacrifican la singularidad, la especificidad o individualidad de millones de seres". En el fondo, o en el extremo, Vasconcelos añora "una como telepatía para revelar con lealtad la más humilde de nuestras percepciones", ${ }^{25}$ que nos dé la "posibilidad de distinguir la multitud de las creaciones, asociándolas a la multitud de las palabras que probablemente sirvieron a Dios para engendrarlas." ${ }^{26}$ Una telepatía con Dios sería en efecto preferible, digo yo, pero ya la telepatía con otros hombres sería bastante maravillosa.

Estas ideas, como es obvio, no son muy certeras ni como crítica de la fenomenología husserliana ni, sobre todo, como propuesta de un nuevo tipo de

\footnotetext{
${ }^{20}$ En las primeras páginas de su Todologia.

21 Vasconcelos, Lógica orgánica, en Obras completas, vol. IV, p. 496.

22 Todología, ed. cit., p. 856.

23 Ibid.

24 Ibid., p. 858.

${ }^{25}$ Ibid.

${ }^{26}$ Ibid., p. 859.
} 
lenguaje. Se critica en ellas a la fenomenología como si ésta fuera el pecado original y la reducción fenomenológica fuera la abstracción que toda comunicación lingüística exige. Sin embargo, sirven como muestra de lo que puede significar, de lo que ha significado, ese simple propósito, o proyecto, de evitar las generalizaciones del lenguaje $-\mathrm{y}$ de lo que estas generalizaciones pueden llegar a doler-. Vasconcelos, recordemos, vincula a esto toda una concepción del mundo. Si hubiera excluido de su propuesta ese intento delirante de forjar un vocabularịo infinito, habría logrado mejor su propósito de invitarnos a ver la realidad sin ningún lenguaje en absoluto, de darnos el atisbo de lo que hay, inexpresable, más acá del lenguaje. Sólo que para él esto no es sólo algo inefable; es algo místico. Un poco más adelante trataré de acercarme a la situación en que realmente nos coloca Vasconcelos.

Recordemos el dictum de Husserl: "jamás puedan reflejarse en la expresión todas las particularidades de lo expresado". ¿Qué es lo expresado? En el caso normal y más simple de una percepción, se expresa esta percepción misma, diciendo por ejemplo "El mirlo echa a volar". Lo expresado es una vivencia porque es en ella donde habita el sentido y a ella se le adherirá la intención propiamente expresiva como un estrato superior; pero en esa expresión se dice o se predica algo del objeto de esa vivencia. Por eso puede decirse también que se expresa el nóema de la vịvencia, y expresarlo implica su "conversión" en significación, su "conceptualización". A Ahora bien, hay dos acotaciones que deben tomarse en cuenta. La primera es que no se trata de todas las vivencias, ni siquiera de todas las vivencias intencionales. Son expresables sólo los actos, es decir, las vivencias actuales, que son aquellas que son ejecutadas por el yo, aquellas en que el yo "está presente" como pólo de irradiación (de irradiación de la vivencia misma, claro está). La expresión misma, o el expresar, es también un acto, o "una capa particular de actos" a la que pueden adaptarse "todos los restantes actos". ${ }^{27}$ El acto no implica la expresión (no necesariamente se expresan los actos, y a veces no pueden hacerlo, como los actos que viven los animales), pero toda expresión es expresión de un acto... Esto no parece ser una limitación muy seria, ya que todas las vivencias no actuales pueden convertirse en actuales: el campo de la inactualidad es un campo de potencialidad. Así pues, también las vivencias no actuales son expresables, previa su conversión en actos. Sólo que no son expresables en su calidad de no-actos, mientras se mantienen como tales. $Y$ resulta que todo acto, toda vivencia actual, está siempre rodeado "de un 'halo' de inactuales". ${ }^{28}$

27 Hua III/1, 286.

${ }^{28} \mathrm{Hua}$ III/1, 73. 
Y aunque éstas estén "siempre prestas" a pasar "al modo de la actualidad", 29 mientras no pasen a él no son expresables. (Esto, por cierto, abre la interesante cuestión de la posibilidad de la expresión de un yo dormido. ¿No hablamos dormidos a veces? ¿No nos expresamos auténtica o propiamente cuando así hablamos? La cuestión tiene que ver con la de la relación en que está el yo con sus vivencias inactuales, con su conciencia dormida o sorda; pero no podemos abordarla aquí). ${ }^{30}$ Lo que importa señalar es que, en el momento de la expresión, en el momento, pues, de hablar o de escribir, no se expresa simultáneamente el halo de vivencias inactuales que rodea a la expresada, no se expresa, pues, su horizonte. Esta acotación nos lleva a la segunda, que es, en mi opinión, de tal alcance que resulta decisiva y suficiente para efectuar el deslinde entre lo decible y lo indecible..., con algunas explicitaciones. Curiosamente, Husserl la enuncia en pocos lugares, y siempre en frases incidentales, o entre paréntesis. Se trata de esto: lo expresable son, como dijimos, los actos, pero no los actos completos, sino sólo su núcleo noemático. Ya antes citamos la frase: "toda mención en sentido noemático ( $\mathrm{y}$ en verdad en cuanto núcleo noemático) de un acto cualquiera es expresable mediante 'significaciones". ${ }^{31}$ En la misma página, casi en seguida, caracteriza la expresión así: “"Expresión' es una notable forma que consiente ẹ adaptarse a todo 'sentido' (al 'núcleo' noemático) y lo eleva al reino del 'logos', de lo conceptual, y con ello de lo 'general".

Este núcleo noemático, también llamado "sentido objetivo" del acto, u "objeto intencional en cuanto tal", no tiene que ser, o referirse, a un solo objeto simple: puede ser una montaña, una arboleda, una ciudad, una galaxia..., pero si nos mantenemos en la esfera de lo real, en la realidad (la Realität), se trata siempre de algo individual. Pero justamente la expresión, al adaptarse al "sentido" de la vivencia que se lleva a expresión, a su "núcleo" noemático, lo eleva "al reino del 'logos', de lo conceptual, y con ello de lo 'general". 32 Por esta "elevación" puede ser expresado. Pero la elevación misma, aunque no altera en nada la individualidad del objeto, y aunque ni siquiera pueda decirse que la ignore en ningún sentido, o la deforme, o la tergiverse, sí la deja de tomar en cuenta en un sentido peculiar. Simplemente, no la "recoge", y no puede "recogerla" jamás. No importa que se refiera a ella o la reconozca, en una expresión que diga, por ejemplo: "Este árbol singular que está aquí delante,

29 Hua III/1, 73.

${ }^{30}$ Un yo dormido es un yo que no vive actos. No puede identificarse con el yo que sueña, que es un yo que sí ejecuta actos y que es por ende, en sentido fenomenológico, un yo despierto o en vigilia. Aquí queda pendiente la cuestión de si debe distinguirse entre un yo que sueña y un yo soñado, y también la de la identificación entre el yo despierto y el dormido.

31 P. 286.

32 P. 286. 
con tales y cuales características...". El árbol está ahí delante para la vivencia en que es percibido, pero la individualidad misma del árbol -y justo en cuanto la individualidad que es para esa vivencia misma, no como una supuesta individualidad "objetiva" o en sí-, abarca mucho más que el hecho de ser un árbol que está ahí delante con tales y cuales características, y por ende la expresión que pronunciamos podría ser empleada para referirse a muchos otros árboles en situaciones individuales distintas.

La expresión del núcleo noemático respeta el sentido objetivo de la percepción, en la cual se encierra cierta determinación del objeto que también podríamos denominar "nuclear". Pero para la conciencia, el objeto, o su individualidad o su situación individual, está siempre determinado, por encima de su mera determinación nuclear, por un sinnúmero de factores y elementos que componen lo que Husserl llama el "nóema pleno" (correlato de una "nóesis plena" o, podemos también decir, "vivencia plena"). Es este nóema pleno lo que, como tal, es indecible. $Y$ esto se desprende, de modo muy directo, de la tesis husserliana de que es el núcleo noemático lo elevado por la expresión al reino del logos, de lo conceptual. Pues el nóema pleno es el nóema completo, y no sólo su núcleo.

Y de aquí resulta también sencillo derivar, como diáfano corolario, esta otra tesis o serie de tesis: puesto que durante toda nuestra vida no vivimos nunca sólo en vivencias nucleares, que posean como único elemento un núcleo noemático, sino siempre en vivencias plenas, con nóesis plenas y nóemas plenos, entonces la vida, tal como la vivimos a cada momento de nuestras vidas, es inefable, y podemos ya darle una respuesta, todavía parcial y no completamente asimilada, pero ya firmé, a José Gaos: para la fenomenología, lo indecible es la vida tal como concretamente se vive $-\mathrm{y}$ junto con ella su correlato, tal como es correlato de ella, llámese árbol, mirlo, prado, mundo, realidad, naturaleza-. Pero digo que ésta es una respuesta parcial y no completamente asimilada porque todavía hay mucho que comprender en estas tesis y muchos complementos que darles.

Hagamos por un momento a un lado los tecnicismos, y acerquémonos sólo un poco a esa vivencia plena con su nóema pleno, a esa vida que digo que es indecible, vista desde la fenomenología. Puede ser una percepción de ese mirlo que echa a volar. Aun considerándola como pura percepción de mirlo, las determinaciones de su objeto son siempre más de las que es posible expresar en un momento dado: si decimos "mirlo de cuello blanco", queda fuera el preciso matiz de blanco, su relativa grisura o amarillez, su precisa ubicación en el lugar del cuello, etc.; queda fuera la disposición de la cola, el tamaño, la manera repentina de encoger las patas y tender las alas; y ya fuera del núcleo, del mirlo mismo, tenemos la rama desde la que echa a volar, la precisa conformación del terreno en que se encuentra, el color del cielo, la calidad de la luz, 
el juego de sombras de las nubes, o de las ramas de los árboles cercanos, etcétera. La riqueza de esa simple percepción, considerada sólo como percepción, es ya de tal magnitud que ni Funes el memorioso con toda su memoria podría terminar nunca de expresar todos sus detalles. Pero hay que considerar que la vivencia es sólo percepción en cuanto a un núcleo central (un núcleo de otra especie): porque a la vez que percibe también recuerda, activa o pasivamente, otras cosas, otros paisajes, otros mirlos o no mirlos, y espera, espera algo con respecto al mirlo y algo con respecto al paisaje, a las nubes, o con respecto a otras presencias o ausencias que determinan esa circunstancia concreta; y a la vez que percibe y recuerda y espera, también puede sentir agrado o desagrado, curiosidad o desinterés, entusiasmo o tedio. Y todo esto ocurre en cierta superficie de la vida de conciencia, una vida que tiene también, en todo momento, múltiples trasfondos, horizontes, pasividades, entretelas. Basta pensar en la diferencia en la manera como perciben y viven esa percepción del mirlo (en el mismo lugar y bajo la misma luz, desde el mismo sitio y con las mismas perspectivas geográficas) el ornitólogo que lo observa con interés o pasión teóricos y para quien esa observación precisa será fuente de ciertas confirmaciones, discusiones, refutaciones; el hijo de pocos años del ornitólogo que ya se hartó de acompañar al padre en sus excursiones y para quien esos pájaros no significan nada más que pájaros; o el ayudante del ornitólogo, o el hijo mayor, que está preocupado por imitar al ornitólogo en su manera de apostarse, de aguardar, de guardar silencio, de anotar y registrar sus observaciones, etc. El intrincamiento vivencial de una simple vivencia instantánea o momentánea es en cualquier caso tan complejo que se justifica la afirmación de Adolf Reinach: "Aun la vida conciente más pobre es ya demasiado rica como para que su sujeto la pueda captar plenamente".

Ahora bien, hay que ver que la inefabilidad de la vida, o de cada una de las vivencias de su curso, no depende precisamente de la infinita riqueza de motivos, de la cantidad infinita de determinaciones, capas y momentos de sentido que la componen como vivencia plena. Por sí misma, esta riqueza, por grande que sea, no define más que una inefabilidad cuantitativa, una inefabilidad que lo es sólo de hecho, contingentemente, aunque de hecho sea también perfectamente insuperable. Ésta sería superable, precisamente, sólo en una expresión sin fin que detallara y particularizara cada vez más lo expresado. La inefabilidad cualitativa, o esencial, o auténtica, depende más bien del hecho de que esa enorme combinación de elementos, momentos, sentidos y fragmentos de sentido, es vivida a la vez, y de manera absolutamente irrepetible, por un solo sujeto, quien por eso mismo no puede hacer partícipe de ella a ningún otro.

Hace falta indagar y describir en detalle cómo esa combinación de factores y elementos, esa complejidad e intrincamiento en la corriente de la vida de conciencia, la trama concurrente de múltiples síntesis de múltiples 
niveles y dimensiones, singulariza radicalmente cada uno de sus momentos, de suerte que también ellos, cada uno de ellos, y no solamente la corriente en su conjunto, resultan ser absolutamente únicos e irrepetibles. Esta unicidad o singularidad, e irrepetibilidad, absolutas, implican la imposibilidad de la participación, o sea, de la comunalización, o sea, de la comunicación. Son comunicables sólo determinaciones más o menos aisladas de una vivencia o de una síntesis vivencial, pues ellas pueden ser convertidas en objeto, y por ello en parte del núcleo noemático, de un acto, y gracias a ello ser conceptualizadas y expresadas. Pero esto no puede hacerse con respecto a ninguna vivencia plena, dada la manera como en ella se han empozado o sedimentado, como tienen aún cierto modo de vigencia, todos los actos ya vividos; es decir, la manera como lo que se llama la historia o la experiencia del sujeto determina en cierto sentido su mismo ser presente. "Historia" no se entiende aquí en el sentido de un relato o una narración, sino en el de decurso vivencial.

En este punto, la fenomenología deberá revisar y sancionar la rica historia de la ontología que desde la escolástica dejó sentado que el individuo es inefable (individuum est ineffabile). Pero no ha habido una sola teoría de la individuación, y ni siquiera una sola manera de entender este mismo apotegma. La fenomenología del lenguaje tiene que enlazarse con la entera fenomenología constitutiva trascendental para abordar los muy serios problemas de la relación entre la experiencia, o la vida, y la individuación, y no sólo la individuación del sujeto mismo, sino también de los objetos que son sus correlatos $y$, finalmente, del mundo en cualquier sentido en que se tome.

Para esa indagación, es fundamental la de la experiencia pre-predicativa o pre-lingüística, la de la constitución en ella de las primeras determinaciones objetivas, de las primeras tipificaciones y generalizaciones y de la manera como fungen de basamento para la generalización propia de la conceptualización expresiva, lógica y lingüística. $Y$ es también fưndamental, por otro lado, la comprensión fenomenológica de la participación de los otros sujetos en cada uno de los niveles de la constitución de la realidad (y de cualquier otro "mundo", o de el mundo), pero sobre todo en el origen y la evolución de lo que puede llamarse "intención lingüística", desde el primer conato de comunicación en el habla más simple, hasta la conformación de la lengua como institución simbólica madura.

El enorme peso de la participación del lenguaje en la "construcción de la realidad" ha sido insistentemente denunciado en la filosofia. La denuncia de Nietzsche no ha sido de las menos poderosas e interesantes, por más que esté hecha sobre supuestos ontológicos y epistemológicos muy dudosos. Una revisión fenomenológica de esa denunçia, o de toda la investigación nietzscheana sobre el origen del lenguaje, que es a la vez el origen de la conciencia (en su sentido) y de la vida en comunidad, facilitaría mucho la compren- 
sión de lo que quiero proponer como una crítica fenomenológica del lenguaje. Si le doy ese nombre no es precisa ni principalmente para ponerla en la línea de la crítica de Nietzsche, o de la que desarrolló Fritz Mauthner por los mismos años pero, por lo que se me alcanza, sin ningún contacto con la de Nietzsche. Más bien le doy ese nombre para ponerla en el tenor de lo que Husserl llamaba crítica de la razón, con el propósito original de hacer una estimación de sus fines, de su alcance y de su sentido. Pero bien visto, esa crítica no es otra cosa que la fenomenología misma del lenguaje.

No hay tiempo para exponer pormenorizadamente el repertorio de sus problemas. Sólo indicaré, para terminar, algunas de sus metas. Una de las principales será, como insinué más arriba, la extensión al lenguaje de la vida ordinaria de los desarrollos logrados por Husserl en relación con el lenguaje científico y su lógica. Esto es particularmente pertinente si se tiene en cuenta que, aunque la comunicación lingüística tiene una importante participación en la constitución objetiva, la vida humana, e incluso interhumana, no es sólo siempre previa al lenguaje en un sentido genético, histórico o cronológico, sino que siempre también vive a su lado, en desbordamiento perenne de lo expresable. Esto quiere decir que la vida no es sólo o bien vida pre-lingüística o bien vida lingüística, como si una vez surgido el lenguaje toda la vida quedara de algún modo marcada por él. Esto es cierto sólo hasta cierto punto. Pero aun entonces, es cierto también que la vida transcurre inefablemente al lado o en medio del lenguaje, cabe lingüísticamente. La fenomenología del lenguaje tiene que asentarse, necesariamente, en una fenomenología de la vida en su plenitud inefable.

No quisiera, con todo esto, que se viera en esta propuesta de una crítica fenomenológica del lenguaje una sugerencia mística, y tampoco un elogio del silencio. Mauthner escribió: "[Y] la naturaleza es enteramente muda. Y mudo se quedaría también quien la comprendiera". ${ }^{33}$ Me temo que también el "pensamiento paradisiaco" de Vasconcelos termina en la mudez. Yo no quiero enmudecer ni que nadie enmudezca. Al contrario. La fenomenología sólo puede desarrollarse lingüísticamente. Las vivencias sobre cuya inefabilidad he querido llamar la atención son nuestras vivencias de todos los días y de cualquier momento. Mirarlas a la luz de su inefabilidad no las trastoca ni les quita lo ordinario. Ni las calla, en la medida en que ellas pueden expresarse. Ciertamente, la reflexión fenomenológica que se requiere para mirarlas así no es ella misma ordinaria. Sin embargo, su excepcionalidad no puede aspirar a conquistar una nueva y extraordinaria individualidad magnífica, nietzscheana

${ }^{33}$ Fritz Mauthner, Contribuciones a una critica del lenguaje, Trad. de José Moreno Villa, Barcelona: Herder, 2001, p. 72. 
o no nietzscheana. Basta con la que ya todos vivimos, en soledad o en compañía. Ésta es la que hay que comprender para aprender a comprendernos: comprendernos a nosotros mismos y sobre esa base comprender a los demás. Se trata sólo de ver si es posible mejorar con ello nuestro común estado de mutuo desencuentro. Quizá un lenguaje que, gracias al lenguaje fenomenológico, ha tomado conciencia de sus límites, pueda despojar de su verdad (la verdad que tenga) a esta frase de Mauthner: "Los hombres, con el lenguaje, han conseguido no poderse conocer nunca unos a otros". ${ }^{34}$

Coloquio de Fenomenologia: Retos y perspectivas actuales

Universidad Veracruzana, Xalapa, Ver., 24-26 de noviembre, 2010

\begin{abstract}
Taking as a point of departure José Gaos' claim, most likely directed to Phenomenology, that every true philosophy should produce a theory of what is sayable and what is unsayable, I try to circumscribe, from Phenomenology, and specifically from Husserl's analysis of linguistic expression in Ideas I, an essential unsayability (or ineffability), as a precise limit of language. This limit is brought about by the generality of expression. After a brief historical review, and a exposition of José Vasconcelos' idea of an "inverted epoje" as a way to avoid the generalizations of language, the limit between the sayable and the unsayable is found in the distinction between the noematic nucleus of an act and its full noema, which supports its individuality. As a corollary of this exposition, it is shown that what is ineffable is life itself, as it is concretely lived. On this basis, it is proposed a phenomenological critique of language, according to which a phenomenology of language must be supported by a phenomenology of life in its ineffable plenitude.
\end{abstract}

